\title{
Probation linked supervised disulfiram in the treatment of habitual drunken offenders: results of a pilot study
}

\author{
COLIN BREWER, JOHN SMITH
}

\begin{abstract}
Sixteen habitual drunken offenders agreed to take disulfiram in liquid form under supervision as a condition of a probation order. They knew that failure to take medication, as with failure to observe any other condition of probation, could result in their being returned to court. Three defaulted but only two of the remainder committed further offences. Nine were entirely successful. At the end of the study the average period of abstinence for the whole group was 30 weeks compared with six weeks during the previous two years. Nine risked drinking alcohol but none suffered any serious consequences or side effects.

This technique may be a judicially acceptable and more hopeful alternative to prison for these offenders.
\end{abstract}

\section{Introduction}

If there is doubt about the specific effectiveness of most methods of treating the average alcoholic patient, ${ }^{12}$ there is even more doubt in the case of habitual drunken offenders. These subjects are widely regarded as having little motivation for treatment: many are homeless, socially isolated, and unemployed. Even when sober some are unemployable or have other psychiatric disorders.

Of the few controlled outcome studies, the only British one was not encouraging. ${ }^{3}$ Scottish men arrested for drunkenness were randomly allocated either to the normal court procedure or to a detoxification centre which it was hoped would be the start of a programme of rehabilitation. The subsequent drinking behaviour of the treated group, however, did not improve. Neither penal measures nor, in many cases, psychiatric treatment and membership of Alcoholics Anonymous seem to have much effect on this group. Many have spent at least some time on "skid row." Virtually the only rays of optimism to brighten this Hogarthian scene of desolation and despair emanate from two American reports.

Bourne et al $^{4}$ studied 132 habitual offenders in Atlanta who agreed to take supervised disulfiram as a condition of probation as an alternative to one month in prison. Of these, 71 took disulfiram for the agreed 12 weeks; and the authors noted

Community Alcoholism Treatment Service, Westminster Hospital, London SW1

COLIN BREWER, MB, MRCPSYCH, director

Inner London Probation Service

JOHN SMITH, probation officer

Correspondence to: Dr Colin Brewer. "several patients who had served as much as ten years ... in consecutive 30 day sentences but who, after starting disulfiram, had remained abstinent for several months and had been able to hold steady jobs. ..."

Haynes $^{5}$ reported on 141 consecutive habitual offenders in Colorado Springs who were asked to choose between the usual 90 day sentence and 12 months of supervised disulfiram given in solution twice weekly at the probation office. Only three chose prison. Of the other 138, at least 66 took disulfiram regularly, though the average period of abstinence was not clear. The annual arrest rate fell from an average of 3.8 per offender to $0 \cdot 3$.

These encouraging findings are rarely referred to in reports on alcoholism and alcoholic offenders. This may be related to the widespread opposition to the use of disulfiram among many physicians and agencies concerned with alcoholics, which in our view is unjustified. Although unsupervised disulfiram probably has little or no specific effect, in the past 10 years evidence has accumulated that supervised disulfiram may be highly and specifically effective.$^{6-8}$ We carried out a pilot study to see if these American findings had any relevance for habitual drunken offenders in central London.

\section{Subjects and methods}

Eighteen habitual offenders well known to the probation service were offered treatment between March 1982 and March 1983. They represented virtually every current offender seen by JS and four seen by other officers. The local courts, however, do not usually refer simple "drunk and disorderly" offenders to the probation service. Thirteen had served at least one prison sentence (average 6.3 sentences) for typical alcohol related offences such as theft, deception, or violence while drunk or to obtain money to continue drinking. Twelve had attended Alcoholics Anonymous groups or had received treatment in psychiatric hospitals for alcoholism. All were referred for probation reports pending trial or sentencing by inner London courts-mainly magistrates'. In at least 14 cases a prison sentence of several months would normally have been expected. They were told that taking supervised disulfiram might help them to abstain from alcohol and that if they abstained until their cases were heard the medical and probation reports would probably recommend taking disulfiram under supervision for a year as one of the conditions of a probation order. No guarantees about the court's decision were, or could be, given.

Their average age was 41 years (range 27-51). Only two were employed, and 13 had not worked for at least 12 months. Five had been unemployed for more than five years. Fifteen were or had been physically dependent on alcohol. Fourteen were living in hostels, or worse. Only one had abstained from alcohol outside prison for more than 18 weeks in the previous two years, and the average maximum duration of abstinence in that period was six weeks. Eight had never abstained for more than two weeks.

One patient declined disulfiram. Another absconded from his bail hostel after taking disulfiram for a week. This report describes the progress of the remaining 16 , whom we followed up for a minimum 
of 12 weeks from their first dose of disulfiram. In all cases the courts accepted our recommendations about treatment and probation. It was made clear to the patients that failure to take disulfiram would be a breach of probation for which they could be brought before the court again.

\section{Results}

Despite oral and written warnings, and in several cases a medically supervised alcohol challenge, nine of the 16 subjects tried drinking alcohol, generally in the first two weeks. Most got a severe reaction and did not repeat the experiment. In the remainder the dose of disulfiram was increased until they stopped drinking. Some needed as much as $800 \mathrm{mg}$ daily (average $365 \mathrm{mg}$ daily). Once established on an adequate dose, ${ }^{9}$ nine of the 16 were completely successful, adhering closely to the conditions of their probation order. Two others had only a brief lapse without offending and subsequently complied consistently after a warning.

Three patients consistently refused to continue taking disulfiram after two, 12, and 18 weeks of treatment respectively. Two were arrested and imprisoned for breach of probation before they could commit further offences. After leaving prison one again began to take supervised disulfiram.

Only two patients were charged with new offences while receiving treatment. One, a transsexual, refused medication three weeks after starting treatment and a few days after receiving a probation order. Owing to administrative delay she was not immediately arrested, got drunk, and shoplifted again. She was fined for theft and the breach of probation but subsequently complied consistently for over 22 weeks (longest previous abstinence six weeks). The other patient, a man with a history of illicit drug abuse, evaded medication because of inadequate supervision at a time of exceptional stress. He was committed to prison awaiting trial for stealing drink but was willing to resume disulfiram when free to do so.

Twelve of the 16 patients were therefore either completely successful in abstaining or had only brief and comparatively harmless lapses. At the end of the pilot study the average abstinence for the entire group, including those who failed, was 30 weeks and all but one had already exceeded their longest abstinence out of prison in the previous two years, when they averaged six weeks.

\section{Discussion}

These results are at least as encouraging as those reported by Bourne et al and Haynes. Only three of our 16 patients consistently refused to take disulfiram compared with $61\left(46^{\circ} \%\right)$ of the patients in Atlanta and $52(37 \%)$ of those reported by Haynes. Yet nine of our patients risked drinking while taking disulfiram as against $33(25 \%)$ in the series of Bourne et al. Our average abstinence of 30 weeks compares with 12 weeks in the Atlanta study, but Bourne et al included patients with a shorter follow up than ours.

Like Bourne et al, we found "not a single serious adverse result either from taking the drug or experiencing the reaction with alcohol," despite the rather poor health of this group. We too observed "old lags" remain sober for months and start to rebuild their lives, when usually their first act on leaving prison was to get drunk again. Several patients asked for their disulfiram to be continued after the probation order expired.

The amount of time spent on psychiatric care was relatively modest. Six patients were admitted to hospital only for drying out (average stay seven days). Once treatment was established, most patients were seen at intervals of two or three months in the outpatient clinic. They generally required less probation work than if they had continued drinking and offending. At the start of treatment disulfiram was usually given in liquid form thrice weekly (with appropriate increases in dosage) at the probation office, but in most cases the task was eventually delegated to other people who were thought to be reliableusually hostel staff; in four cases girlfriends or wives.

We are aware of objections that this technique is "authoritarian," but these patients entered into an agreement without haste and no less freely than in the case of any other probation order. No offender is forced either to start or to continue taking disulfiram, and three patients chose to discontinue it: prison permits no choice at all.

Although this pilot study lacked a control group, patients with such long and well documented histories may serve as their own controls. In any case, the effectiveness of disulfiram in preventing the drinking of alcohol is not in dispute, as many patients in this group discovered to their own discomfort. What we are assessing is the effectiveness of a system which is intended to ensure that what is prescribed is also consumed, and which includes a "fail safe" mechanism. Our experience suggests that the system can be made to work quite well and is readily accepted by a substantial proportion of habitual drunken offenders. Given rigorous supervision of an adequate dose of disulfiram and a swift and predictable response to any defaulting, many of them can evidently be kept sober for worthwhile periods. Interestingly, none of our patients was charged with any offence while abstaining.

Supervised disulfiram facilitates rehabilitation but is not a substitute for it. It is not only cheaper and more humane than prison but probably more effective in reducing the likelihood of future offending - the acid test of any therapeutic intervention in these subjects. According to a recent review," "The story of attempts to deal with the habitual drunken offender over the last 15 years is a sad but revealing one." We think that supervised disulfiram may bring some good news for a change.

\section{References}

${ }^{1}$ Edwards G, Orford J, Egert S, et al. Alcoholism: a controlled trial of "treatment" and "advice." I Stud Alcohol 1977;38:1004-31.

${ }^{2}$ Armor DJ, Polich JM, Stambul HB. Alcoholism and treatment. New York: Wiley, 1978.

${ }^{3}$ Hamilton J. Evaluation of a detoxification service for habitual drunken offenders. Br $\mathcal{F}$ Psychiatry 1979;135:28-37.

4 Bourne PG, Alford JA, Bowcock JZ. Treatment of skid row alcoholics with disulfiram. Quarterly Fournal of Studies on Alcohol 1966;27:42-8.

${ }^{5}$ Haynes SN. Contingency management in a municipally administered antabuse program for alcoholics. F Behav Ther Exp Psychiatry 1973; 4:31-2.

6 Gerrein JR, Rosenberg CM, Manohar V. Disulfiram maintenance in outpatient treatment of alcoholism. Arch Gen Psychiatry 1973;28: 798-802.

${ }^{7}$ Robichaud C, Strickler D, Bigelow G, Liebson I. Disulfiram maintenance employee alcoholism treatment: a three-phase evaluation. Behav Res Ther 1979;14:618-21.

${ }^{8}$ Azrin NH, Sisson RW, Meyers R, Godley M. Alcoholism treatment by disulfiram and community reinforcement therapy. $\mathcal{F}$ Behav Ther Exp Psychiatry 1982;13:105-12.

${ }^{9}$ Brewer C. How effective is the standard dose of disulfiram ? A review of the alcohol-disulfiram reaction in practice. $B r f$ Psychiatry (in press).

10 Smith $R$. The habitual drunken offender; everybody's fool, nobody's friend. $\mathrm{Br} \mathrm{Med} \mathcal{F} 1981 ; \mathbf{2 8 3}: 1251-3$.

(Accepted 18 August 1983)

If the level of liver enzymes in the blood rises during treatment with non-steroidal anti-inflammatory drugs should the drug be stopped?

Not necessarily. Many non-steroidal anti-inflammatory drugs cause an occasional rise in the levels of enzymes thus showing some hepatic effect but not necessarily damage to the liver. This is usually an unpredictable isolated reaction but is occasionally accompanied by other features of hypersensitivity. If severe there may be characteristic changes in the liver of hepatitis or cholestasis. Aspirin in doses over $2 \mathrm{~g}$ daily produces direct hepatotoxicity, and phenylbutazone has been described as causing granulomatous changes. A rise in the levels of enzyme has many causes and if small the drug may be continued and the tests repeated. If the bilirubin level is also raised or the enzyme levels rise to four times the upper limit of normal the warning must be heeded and the drug stopped. If the enzyme levels do not fall after stopping the drug then investigations should be considered to delineate hepatic features of the disease being treated or to look for coincidental liver disease.- J A MATHEWS and R P H THOMPSON, consultant physicians, London.

Keeling PWN, Thompson RPH. Drug-induced liver disease. Br Med $\mathcal{Y}$ 1979;i :990-3. 